\title{
Variation of Speed and Torque Response of Closed-Loop Classical Controlled Different Rated BLDC Motor
}

\author{
Upama Das, Pabitra Kumar Biwas
}

\begin{abstract}
This manuscript proposes a comparative analysis of $B L D C$ motor performance at various ratings. The BLDC motor may act as a replacement for conventional engines such as the Brushed DC motor, the induction motor, the switched reluctance motors, etc. Because of the BLDC motor's overweight merits, modeling is performed to improve system performance. The torque feature of BLDC motor plays an extremely significant aspect in the fabrication of the BLDC motor drive device, so it is crucial to approximation the exact torque value that is calculated by the simulation of the model proposed in MATLAB software. In the MATLAB / Simulink setting, different ratings of BLDC motor are simulated after the creation of the straightforward analytical model of the three-phase BLDC motor with counter electromotive force trapezoidal waveforms. Based on the review, a comparative examination of each valued engine outcome is displayed in the MATLAB environment's Graphical User Interface.
\end{abstract}

Keywords: BLDC motor, mathematical modelling, different Hp motor.

\section{INTRODUCTION}

Brushless DC engines were utilized in numerous manufacturing and household applications. Because of this engine's overweighing merits, there is an ongoing inclination to introduce upgraded control structures to boost engine operation [1]. Models such as the d-q model and abc phase variable models have been established for the study of the BLDC motor drives mechanism under different circumstances. A variety of simulation models based on non-linear state-space equations have been suggested. The BLDC engine deliberated in these models is related to neutral grounding, but several applications need neutral separation. Having regard to the merits of these developments, the motor is modeled in this paper as a star associated with segregated neutral, and the voltages supplied are line-line. Modeling the entire control scheme is useful for performing detailed simulation studies. This paper deals with PWM inverter modeling devices, and BLDC motor controls for different

Manuscript received on February 10, 2020.

Revised Manuscript received on February 20, 2020.

Manuscript published on March 30, 2020.

* Correspondence Author

Upama Das*, Pursuing Ph.D., Department of Electrical and Electronics Engineering, National Institute of Technology Mizoram, India.

Pabitra Kumar Biswas, Department of Electrical and Electronics Engineering, National Institute of Technology Mizoram, India.

(C) The Authors. Published by Blue Eyes Intelligence Engineering and Sciences Publication (BEIESP). This is an open access article under the CC BY-NC-ND license (http://creativecommons.org/licenses/by-nc-nd/4.0/) configurations. The efficiency of this simulation is investigated with a load.

\section{BRUSHLESS DC MOTOR}

The new technology of brushless motors has been assembled up since the 1980s. Based on the counter voltage pattern, the permanent magnet brushless motors are divided into two groups, i.e., Brushless AC and DC motors [2]. BLDC motors are increasingly becoming popular in industries such as Appliances, HVAC, Healthcare, Electrical, Automotive, Aviation, Military, Hard Drive, Industrial Automation and Instrumentation due to their high performance, high-power factor, silent running, lightweight, stable and low-maintenance [1]. In the case that the alternators and brushes feature is removed, the BLDC motor needs a 120-degree model of voltage source inverter through which supply is given and a sensor to locate the rotor orientation to suitably alternate current. The BLDC motor's rotation is built upon the rotor position feedback attained from the magnetic devices. Besides, the BLDC motor utilizes three hall sensors to determine the order of the commutation. The power losses in BLDC motor are in the stator where heat can be quickly removed over the edge or where large machines are depleted for cooling systems. BLDC engines have numerous improvements over conventional direct current and induction-based motors. The highlighting improvements are enhanced speed versus torque characteristics, excellent dynamic response, high efficiency, long working period, noiseless activity, higher speed ranges [2]. To date, more than $80 \%$ of controllers are classical controllers, especially PI type, because they are simple to understand [3]. The speed controls are the traditional PI controllers, and the new controllers are the $\mathrm{P}$ controllers for high-performance driving.

\section{CONSTRUCTION}

BLDC motor is fabricated with a permanent magnet rotor and twisted stator wire poles. BLDC motors are similar to a synchronous device. It means the same frequency of the magnetic field and the stator, which is created by the stator field and the rotor twirls. Thus, BLDC engines don't suffer the "slip" usually seen in induction engines. 


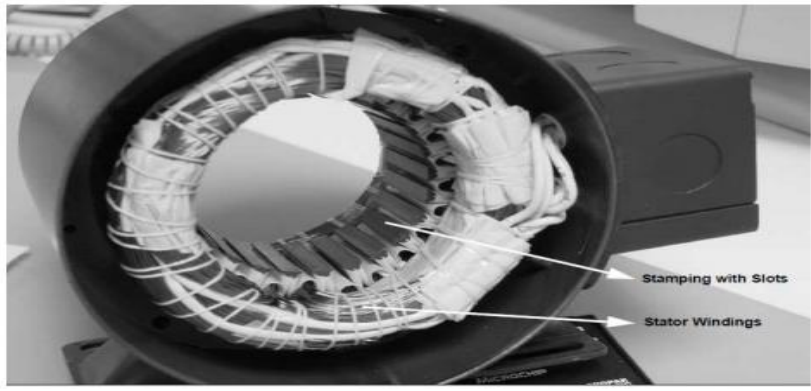

Figure:1 The stator construction of a BLDC motor

\section{A. Stator}

The stator of a BLDC motor, as shown in the figure. 1 contains lined steel coating with conductors retained in the slots perpendicularly intersect the inner perimeter laterally. Such motors are paired in star fashion with three stator windings. To obtain a winding, each of these windings is installed with separate intertwined coils. Any or extra twirls are located in the section and intertwined to create a conductor assembly. Individually these windings are spread above the perimeter of the armature to create a uniform poles count.

\section{B. Rotor}

The rotor is composed with a permanent magnet and can comprise of n number of even pole pairs of alternating North $(\mathrm{N})$, and South (S) poles. Contingent on the correct field concentration in the rotor, the necessary magnetic substance is preferred to form the motor. They use ferrite magnets to produce permanent magnets. Infrequent Earth compound magnets are now becoming common.

\section{Hall Sensors}

A BLDC motor's commutation, as shown in figure-2, is electronically in order. The stator windings should be energized to spin the BLDC motor. To know which conductor will be boosted after the stimulating order, it is vital to understand the location of the rotor. The direction of the rotor is predicted by means of Hall effect sensors mounted in the armature on the motor's non-influential wind-up, as revealed in figure 2. Whenever the magnetic rotor poles appear to close the transducers, they stretch 1 or 0 binary bits, which specifies that the $\mathrm{N}$ or $\mathrm{S}$ pole passes adjacent to the transducers. Grounded on the explanation of these three Hall sensor information, the specific commutation order can be resolute.

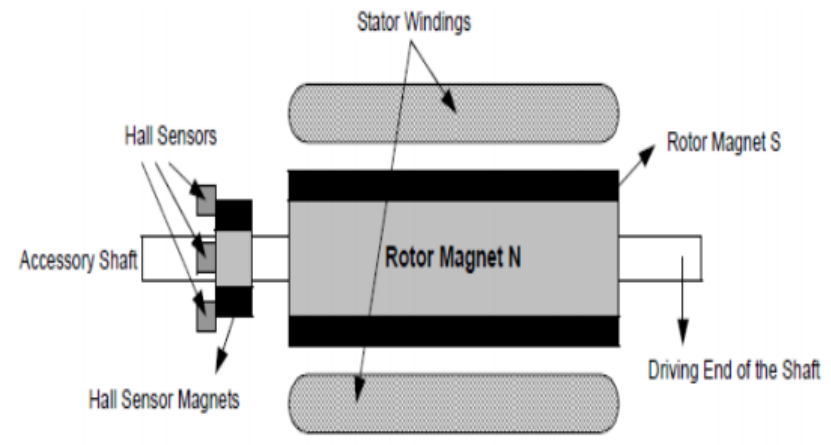

Figure. 2 Rotor and Hall sensors of BLDC motor

\section{THEORY OF OPERATION}

That flipping series is energized to positive power by one of the windings, the second conductor is invigorated to negative, and the third is in a zero-voltage state. According to the communication amid the magnetic field created by the stator wires and the permanent magnets, torque is induced. Preferably, when these two fields are at $90^{\circ}$ to each other, the peak torque happens and descends as the fields pass forward. The magnetic field caused by the conductors should change the arrangement to place the motor successively, as the rotor travels to latch-up with the stator field [9].

The commutation chain, one of the magnetic transducers, adjusts the condition for every 60 electrical angles of revolution. Completing an electric cycle requires six phases. In Synchronous, the phase current switching should be revamped at every 60 electrical degrees. One electrical loop can, however, disagree with a full mechanical rotor revolution. The number of electric cycles to be performed to conclude the pairs of rotor poles calculate a mechanical revolution. For each pair of rotor ends, one electric loop is made. The number of electrical cycles thus matches the pairs of the rotor poles. The BLDC motor is powered using a three-phase bridge inverter.

There are six switches, and these switches should be adjusted according to the inputs of the Hall sensor. The modulation of the pulse width techniques is operated to switch switches ON or OFF. Such signals should be Pulse Width Modulated (PWM) at a rate far better than the motor frequency to adjust the rpm. The frequency of PWM should be at least 10 times that of the engine's highest output. When the PWM service period within the orders is separated, the usual voltage provided to the stator diminishes, thereby the velocity. One gain of containing PWM is that if the DC link emf is much superior to the rated motor emf, the motor can be regulated by reducing the PWM service cycle percentage equal to that of the rated motor voltage. This improves flexibility to the regulator to assemble motors with different rated voltages, and by monitoring the PWM duty cycle, matches the controller's average voltage output, to the motor rated voltage. The motor's speed and torque hinge on the forte of the magnetic field caused by the motor's energetic windings, which depend through them on the current. Hence the rotor voltage (and current) shift would alter the pace of the motor.

\section{MOTOR'S MATHEMATICAL MODELING}

The prototype of a Brushless DC motor can be created identically as per the model of a three-phase synchronous machine. The governing features of BLDC motor are different owing to the presence of permanent magnet on the rotor. The rotor used is the permanent magnet cylindrical rotor, which makes the air gap uniform. The stator constitutes three-phase distributed winding, which is connected in a star fashion. With a BLDC engine, the staring value of the rotor lag angle during which the turn begins and the voltage determines the motor's transient response and its efficiency. 
The lag angle is the slant amid the rotor d-axis and the phase A axis. The lag angle has a linear relationship with the torque angle.

Park's transformation is used to convert phase voltages and current into a reference frame, i.e. (a, b, c to d, q, o). D-axis is taken along the magnet flux with a q-axis proceeding to d-axis by 90 -degree in the case of the permanent magnet.

The required machine-related equations are shortened below, where symbols denote their usual standard significance. The stator voltage of the motor as follows [3]:

$$
\left[\begin{array}{c}
v_{a c} \\
v_{c s} \\
v_{c s}
\end{array}\right]=\left[\begin{array}{ccc}
R_{s} & 0 & 0 \\
0 & R & 0 \\
0 & 0 & R
\end{array}\right]\left[\begin{array}{l}
i_{c} \\
i_{b s} \\
i_{c s}
\end{array}\right]+\frac{d}{d t}\left[\begin{array}{ccc}
L_{a a} & L_{b b} & L_{a} \\
L_{b a} & L_{b b} & L_{b x} \\
L_{c a} & L_{b b} & L_{c c}
\end{array}\right]\left[\begin{array}{l}
i_{a} \\
i_{b} \\
i_{c}
\end{array}\right]+\left[\begin{array}{c}
e_{a s} \\
e_{b x} \\
e_{c s}
\end{array}\right]
$$

Assuming symmetrical phases we have,

$$
\begin{gathered}
L_{a a}=L_{b b}=L_{c c}=L \\
L_{a b}=L_{b a}=L_{a c}=L_{c a}=L_{b c}=L_{c b}=M
\end{gathered}
$$

Substituting the earlier two equations in equation (1),

$$
\left[\begin{array}{c}
v_{c} \\
v_{b c} \\
v_{c s}
\end{array}\right]=R_{s}\left[\begin{array}{ccc}
1 & 0 & 0 \\
0 & 1 & 0 \\
0 & 0 & 1
\end{array}\right]\left[\begin{array}{l}
i_{a} \\
i_{b c} \\
i_{c s}
\end{array}\right]+\left[\begin{array}{ccc}
L & M & M \\
M & L & M \\
M & M & L
\end{array}\right] \frac{d}{d t}\left[\begin{array}{l}
i_{a} \\
i_{b} \\
i_{c}
\end{array}\right]+\left[\begin{array}{c}
e_{a} \\
e_{b c} \\
e_{c s}
\end{array}\right]
$$

The simplified form of equation (4) is shown below,

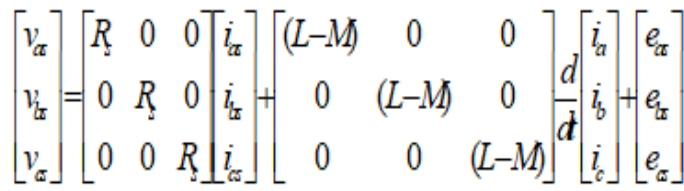

The electromagnetic torque is

$T_{e}=\left[e_{a s} i_{c s}+e_{b s} i_{b s}+e_{c s} i_{c s}\right] \frac{1}{\omega_{m}}$

The relation between speed and electromagnetic torque and load torque,

$$
J \frac{d \omega_{m}}{d t}+B \omega_{m}=\left(T_{e}-T_{l}\right)
$$

The speed and rotor position is expressed as,

$$
\frac{d \theta_{r}}{d t}=\frac{P}{2} \omega_{m}
$$

All of these equations can be expressed as a general state equation,

$x=A x+B u$

Where,

$$
x=\left[\begin{array}{lllll}
i_{a s} & i_{b s} & i_{c s} & \omega_{m} & \theta_{r}
\end{array}\right]^{t}
$$

$$
A=\left[\begin{array}{ccccc}
\frac{-R_{r}}{L_{1}} & 0 & 0 & -\frac{\lambda_{p}}{L_{1}} f_{a}\left(\theta_{r}\right) & 0 \\
0 & \frac{-R_{r}}{L_{1}} & 0 & -\frac{\lambda_{p}}{L_{1}} f_{b}\left(\theta_{r}\right) & 0 \\
0 & 0 & \frac{-R_{r}}{L_{1}} & -\frac{\lambda_{p}}{L_{l}} f_{a}\left(\theta_{r}\right) & 0 \\
\frac{\lambda_{p}}{J} f_{a x}\left(\theta_{r}\right) \frac{\lambda_{p}}{J} f_{b r}\left(\theta_{r}\right) & \frac{\lambda_{p}}{J} f_{a}\left(\theta_{r}\right) & \frac{-B}{J} & 0 \\
0 & 0 & 0 & \frac{P}{2} & 0
\end{array}\right]
$$

$$
B=\left[\begin{array}{cccc}
\frac{1}{L_{1}} & 0 & 0 & 0 \\
0 & \frac{1}{L_{1}} & 0 & 0 \\
0 & 0 & \frac{1}{L_{1}} & 0 \\
0 & 0 & 0 & -\frac{1}{J} \\
0 & 0 & 0 & 0
\end{array}\right]
$$

In equation (12),

$$
\begin{aligned}
& L_{1}=L-M \\
& u=\left[\begin{array}{llll}
v_{a s} & v_{b s} & v_{c s} & T_{l}
\end{array}\right]^{t}
\end{aligned}
$$

The four governing equations are as follows:

$$
\begin{aligned}
& \frac{d i_{d}}{d \theta}=\frac{1}{\omega_{r} L_{d}}\left[\mathrm{v}_{d}(\theta)-\mathrm{ri}_{d}+\omega_{r} \mathrm{~L}_{q q} \mathrm{i}_{q}\right] \\
& \frac{d i_{q}}{d \theta}=\frac{1}{\omega_{r} L_{q}}\left[\mathrm{v}_{q}(\theta)-\mathrm{ri}_{q}+\omega_{r}\left(\psi_{0}+\mathrm{L}_{d^{d}} \mathrm{i}_{d}\right)\right] \\
& \frac{d \theta}{d t}=\omega_{r}
\end{aligned}
$$

$$
\frac{d \omega}{d}=\frac{1}{J \omega}\left[\left(\frac{P}{2}\right)^{2}\left(\psi_{d} \mathrm{i}_{q}-\psi_{q} \mathrm{i}_{d}\right)-f_{m} \omega-\left(\frac{P}{2}\right) T_{l}\right]
$$

Based on the above equations, the simulation models are developed [19].

\section{DETAILED CLOSED LOOP MODEL}

Controller selection plays a vital role in specific applications for much better performance to create a conventional closed-loop system consisting of the quadrature current control system and angular speed control system. Nonetheless, the present loop should run quicker than the backward speed loop so that as a new controller, the PI system is best suited. Numerous classical, functional control approaches, are mentioned in the research works. 
A self-functioned closed loop BLDC motor drive is achieved by using a tachogenerator type transducers, where there is always an awareness of the orientation speed and the maximum speed. This speed controller operates on a visible end electronic potential converter with a regulated dc voltage output (Vdc). A PWM has called topology for the self-synchronous source voltage inverter, which provides switching pulses for the motor drive. In this segment, the development of a system of a self-functioned complicated closed-loop adjustable speed BLDC motor drive that incorporates a self-synchronous VSI supporting mechanism where the inverter is controlled synchronously with the rotor arrangement approximation and the control approach is realized through the manipulation of the sinusoidal pulse width (SPWM) system.

In this projected BLDC motor drive model, the various sub-systems such as inverter architecture, the output of SPWM and complete BLDC motor like torque-speed computing strategy were subsequently modelled and tested. A conventional control mechanism of a traditional BLDC motor drive that forms the current control loop, as well as the speed control loop, plays an important part. Every control system that is centred on a closed-loop integrates feedback. In this section, a theoretical model for the development of two-loop control structures of such a system is provided. In this detailed configuration, the error of the internal controller is supported into the SPWM to which the real rotor speed has pertained. The composite block diagram for the logical form is exhibited in figure-3.

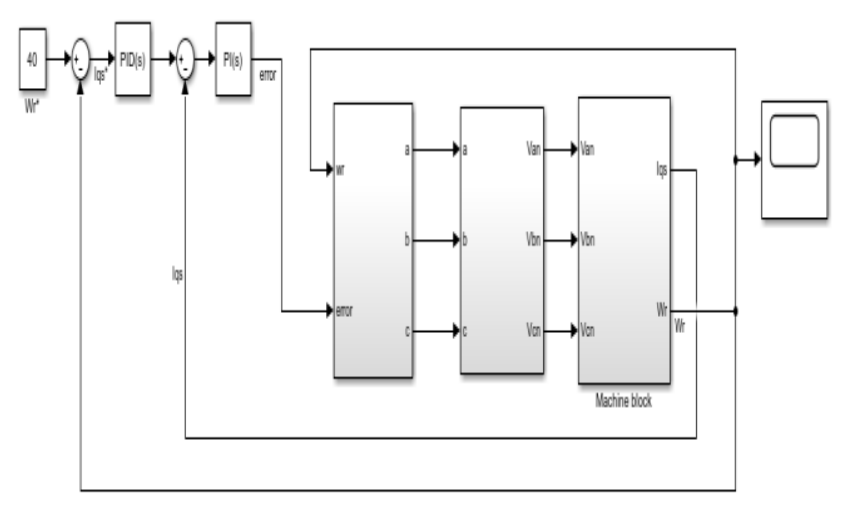

Figure:3 Detailed Closed-loop structure

The detailed design for the planned model development consists of various sub-systems within this diagram. The measurement of the location of the rotor is determined by the electric rotor rpm of the unit. PI's performance of the new control loop system, i.e., error functions as the voltage of the $\mathrm{q}$ axis. The cardinal rule for this proposed model is to maintain the d-axis stator voltage. This accepts the three differential Signals Sa, Sb and Sc. Essentially, these signals are generated by the swapping variations of the PWM guided control strategy and generate the three-phase emfs of $V_{a n}, V_{b n}$, and $\mathrm{V}_{\mathrm{cn}}$. The armature is equipped with the output voltages of the intended inverter driven by the sinusoidal PWM.

The phase voltages which come from the inverter system, i.e., $\mathrm{V}_{\mathrm{an}}, \mathrm{V}_{\mathrm{bn}}$, and $\mathrm{V}_{\mathrm{cn}}$, went on to the BLDC device sub-system unit to calculate the process dynamics. To accommodate another sub-block termed as torque-speed computing block, the machine sub-system layout requires the necessary dynamics. The sub-block calculates both the electromagnetic torque as well as the electrical velocity from the q-axis and $\mathrm{d}$-axis currents. The voltages generated in the armature of a BLDC machine, pretending the engine to be stable defined by the following equations

$$
\begin{aligned}
& V_{a n}=V_{a c}\left(S_{a}-S_{b}-S_{c}\right) / 2 \\
& V_{b n}=V_{a c}\left(S_{b}-S_{c}-S_{a}\right) / 2 \\
& V_{c n}=V_{\dot{\alpha}}\left(S_{c}-S_{b}-S_{a}\right) / 2
\end{aligned}
$$

Where $V_{\mathrm{dc}}$ represents the input voltage of the inverter and $S_{a}$, $\mathrm{S}_{\mathrm{b}} \& \mathrm{~S}_{\mathrm{c}}$ represents the switching combinations of the inverter under various switching instants. The ' $\mathrm{d}$ ' and ' $\mathrm{q}$ ' axis voltages are associated with the flux association recognized by the rotor can be expanded as

$$
\begin{aligned}
& V_{d s}=R_{s} i_{q s}-\omega_{r} L_{q} i_{q s}+L_{d} \frac{d i_{d s}}{d t} \\
& V_{q s}=R_{s} i_{q s}+\omega_{r} L_{d} i_{d s}+\omega_{r} \psi_{0}+L_{d} \frac{d i_{q s}}{d t}
\end{aligned}
$$

The performance of the complete closed-loop drive system can be varied thanks to the current driver and speed controller set. The parameter tuning control strategies, for example, a mix of proportional and integral advantages, will boost drive efficiency.

\section{SIMULATION RESULTS FOR DETAILED CLOSED LOOP MODEL OF DIFFERENT HORSEPOWER}

To select a BLDC motor for the specific application it is necessary for the user to know the rating of the motor with its load-bearing capacity as it helps to reveal the motor's speed and torque. And so, with the variation of rating how the speed and electromagnetic torque differs is necessary to know. The speed and torque response of different horsepower rated BLDC motor is showing below considering the detailed closed-loop model with a load of $10 \mathrm{~nm}$. We know that,

$T_{e m}=J \frac{d \omega}{d t}+T_{l}$

Where $\mathrm{T}_{\mathrm{em}}$ is the electromagnetic torque, $\mathrm{J}$ is the moment of inertia, $\omega$ is the speed and $T_{1}$ is the load torque of a BLDC motor. According to the above electromagnetic torque equation, the steady-state position is reached when the torque of the motor is equivalent to the torque of the load. The steady-state condition for speed is acknowledged by observing the torque curve as at this point the motor electromagnetic torque and load torques are identical. The different motor parameters are assigned according to the different specifications of the rated motor to analyze different speed and torque response under load condition. The horsepower rating of a motor is the mechanical output of the motor which is given by,

$P_{H p}=T_{l} \omega$ 


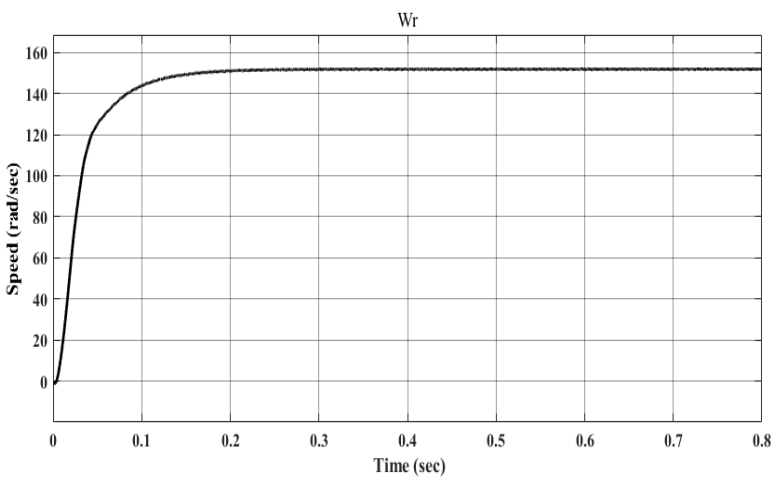

Figure:4 Speed Vs Time response for $2 \mathrm{Hp}$ rating

The above equation-25 clearly signifies that the rating is dependent on the applied load torque and the corresponding speed of the motor. So, a fixed load torque of $10 \mathrm{Nm}$ is considered for three different ratings of motor and the corresponding speed and torque variations are observed. The three considered ratings of BLDC motor are $2 \mathrm{Hp}, 5 \mathrm{Hp}$ and $10 \mathrm{Hp}$.

The simulation results are shown in table-1. The speed of the $2 \mathrm{Hp}$ motor is found to be almost equal to $150 \mathrm{rad} / \mathrm{sec}$, speed of the $5 \mathrm{Hp}$ motor is around $375 \mathrm{rad} / \mathrm{sec}$ and for $10 \mathrm{Hp}$ motor observed speed is $750 \mathrm{rad} / \mathrm{sec}$ as shown in figure-4, figure- 6 and figure-8 respectively. From the torque response plots of figure-5, figure-7 and figure- 9 , it is revealed that the starting electromagnetic torque is having different values for the different rated considered BLDC motors, but all the electromagnetic torques are stabilizing at $10 \mathrm{Nm}$ which is the value of load torque. Thus, it confirms the above-mentioned fact of getting steady-state condition of the system when the electromagnetic torque is equal to the load torque of the motor. As both the electromagnetic torque and the load torque are acting together, so, the final torque is having some ripples which can be eliminated by implying perfect combination of controllers for the closed loop control of BLDC motor drive.

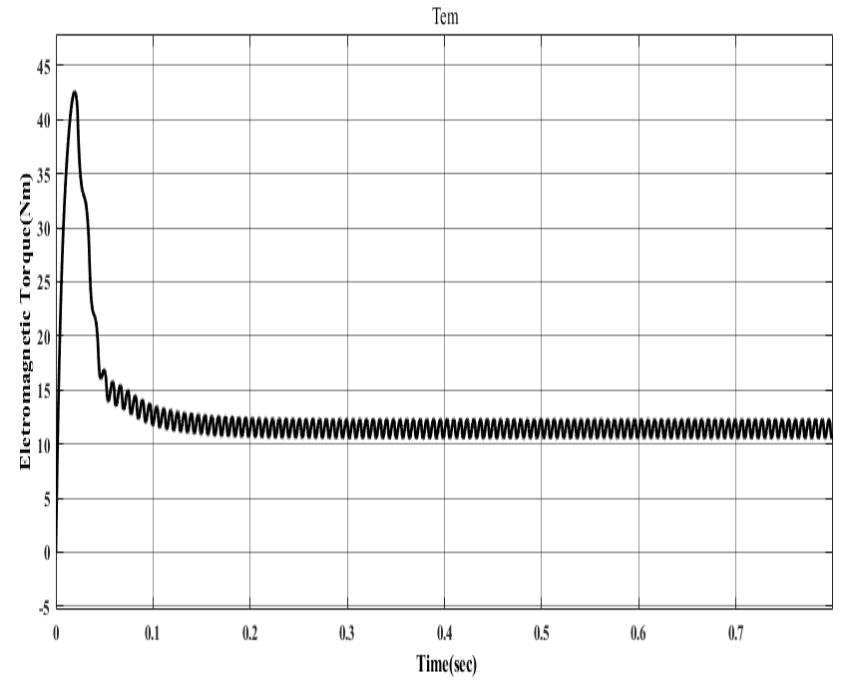

Figure:5 Electromagnetic torque Vs. Time for $2 \mathrm{Hp}$ rating

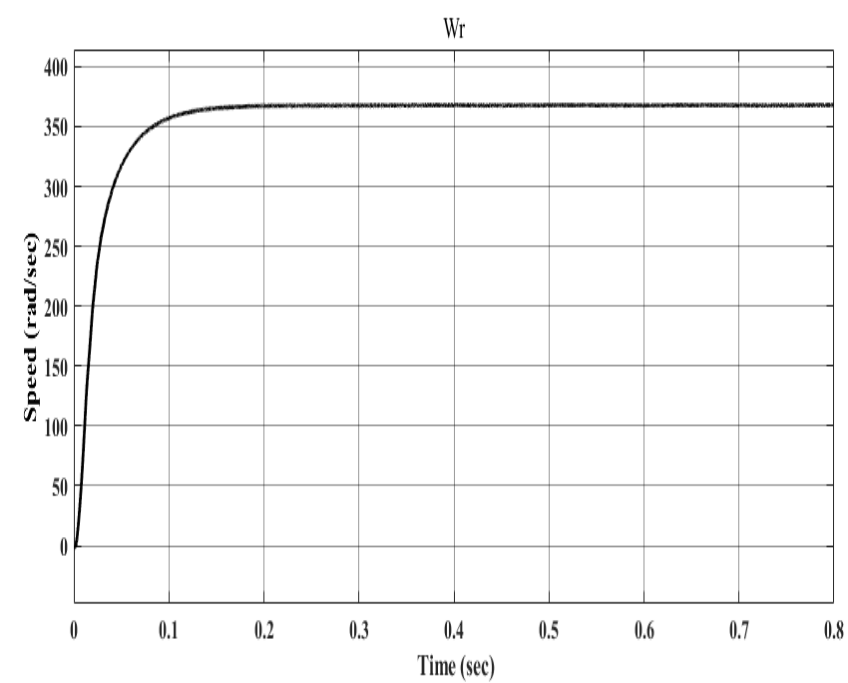

Figure:6 Speed Vs. Time for $5 \mathrm{Hp}$ rating

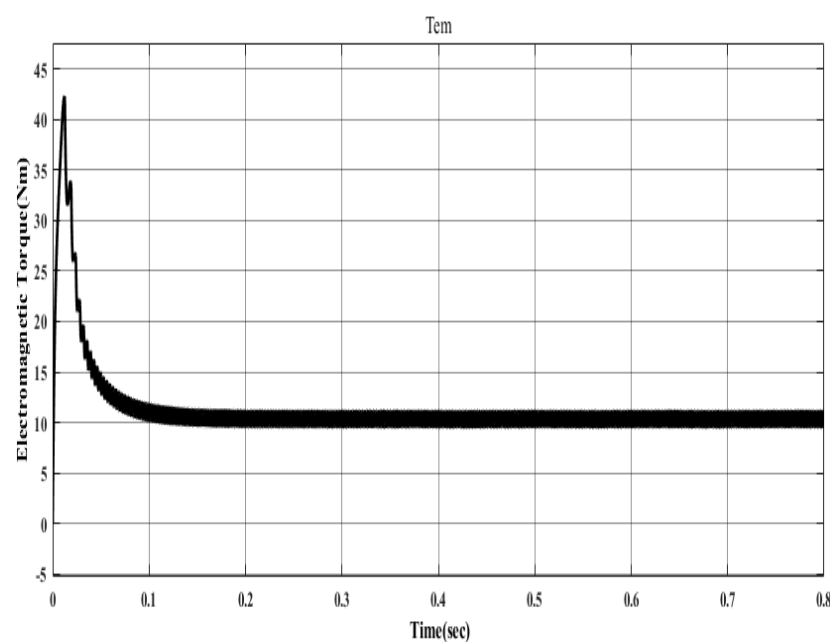

Figure:7 Electromagnetic torque Vs Time 5Hp rating

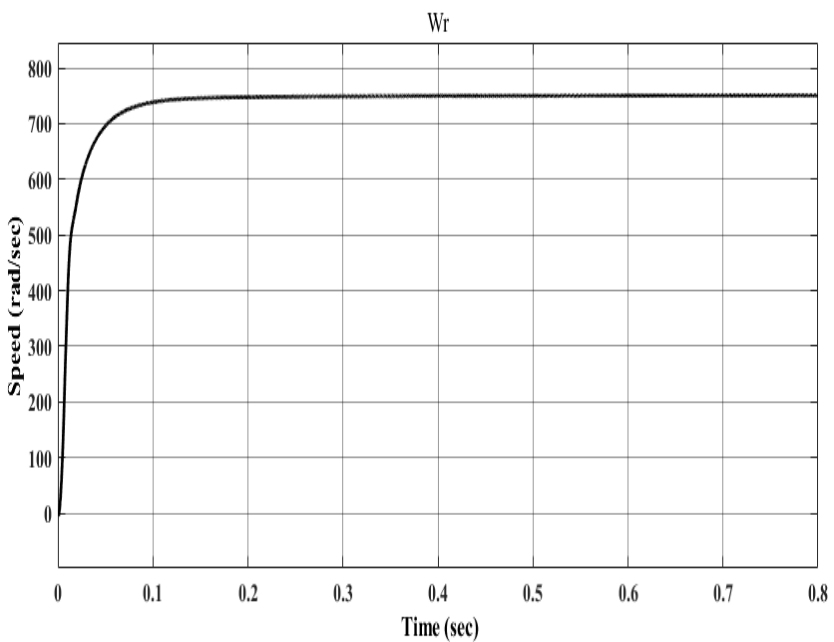

Figure:8 Speed Vs. Time for $10 \mathrm{Hp}$ rating 
Tem

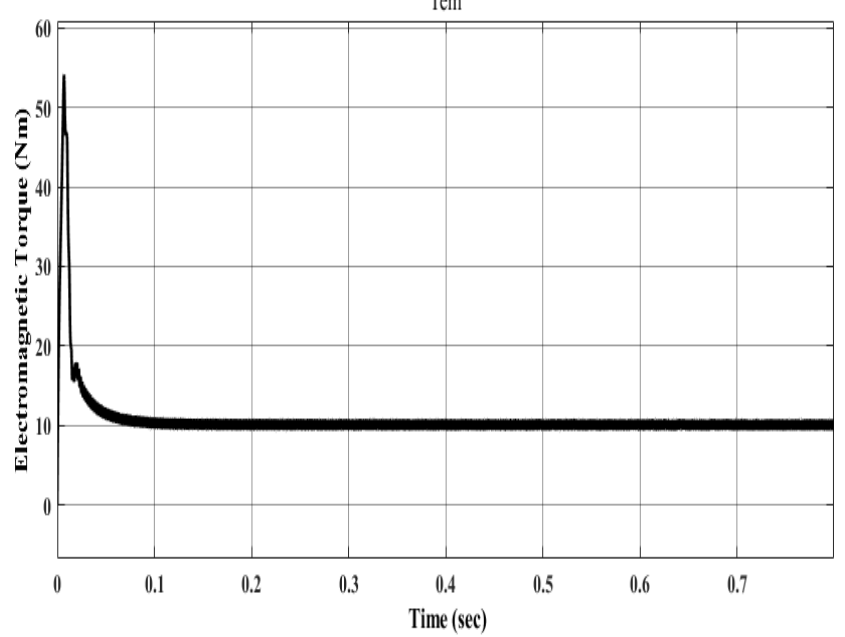

Figure: 9 Electromagnetic torque Vs Time for 10Hp rating

Table:1 Speed and Torque response of Different Rated BLDC Motor

\begin{tabular}{|c|c|c|c|c|c|}
\hline \multirow[t]{2}{*}{$\begin{array}{l}\text { Sl. } \\
\text { No. }\end{array}$} & \multirow{2}{*}{$\begin{array}{c}\text { Power } \\
\text { Rating } \\
\text { (Hp) }\end{array}$} & \multirow{2}{*}{$\begin{array}{l}\text { Angular } \\
\text { Speed } \\
\text { (rad/sec) }\end{array}$} & \multicolumn{2}{|c|}{$\begin{array}{l}\text { Electromagnetic } \\
\text { Torque (Nm) }\end{array}$} & \multirow{2}{*}{$\begin{array}{c}\text { Load } \\
\text { Torqu } \\
\text { e } \\
(\mathrm{Nm})\end{array}$} \\
\hline & & & Starting & $\begin{array}{c}\text { Steady } \\
\text { state }\end{array}$ & \\
\hline 1 & 2 & 150 & 42.57 & 10 & 10 \\
\hline 2 & 5 & 375 & 42.29 & 10 & 10 \\
\hline 3 & 10 & 750 & 54.11 & 10 & 10 \\
\hline
\end{tabular}

\section{CONCLUSION}

This dissertation emphasizes on a relative functioning evaluation of a closed-loop illustration of a Brushless DC Motor drive software coding in MATLAB between various graded BLDC engines. The different framework of the BLDC motor platform was also addressed. The comprehensive SPWM-based system is designed for a BLDC-based trapezoidal back motor based on the EMF, thereby supplying the motor with a 3-phase 120-degree VSI mode. This manuscript portrays the two relevant parameter responses for the load condition of a closed-loop depiction of the mentioned system, and those two responses are speed response and torque generated. The DC link emf to the inverter be able to adjust to improve the BLDC motor velocity regulation in closed-loop mode and is almost the identical as the similarly exciting traditional brushed motor speed manipulation through the operation of the armature emf. Alternatively, some additional variable up-gradation can be performed to get an extraordinary speed and torque reaction for every circumstance. This article enhances the idea of the speed and torque actions of the drive in a closed-loop manner for different rating conditions.

\section{REFERENCES}

1. Pillay, P., and R. Krishnan, "Modeling of permanent magnet motor drives", IEEE Transactions on Industrial Electronics35.4: 537 - 541, 1988.

2. Lu, C. W. "Torque controller for brushless DC motors." IEEE Transactions on Industrial Electronics46.2: 471 - 473, Apr. 1999.

3. R.Krishnan, "Electric Motor Drives Modeling, Analysis, and Control, Prentice-Hall International Inc., New Jersey, 2001.
4. M. Markovic and Y. Perriard, "Simplified Design Methodology for a Slotless Brushless DC Motor", IEEE trans. on Magnetics, vol. 42, no. 12, pp. 3842-3846, December 2006

5. W. Dongmei, G. Haiyan, and Y. Jing, "Modeling and Simulation Research of Brushless DC Motor open-loop Speed-adjustment System", International Conference on Intelligent Control and Information processing, vol.1,pp.394-398, July 2011.

6. T-S Lee, J-H Liu, "Modeling and Control of a Three-Phase Four-Switch PWM Voltage-Source Rectifier in d-q Synchronous Frame", IEEE Transactions on Power Electronics, Vol. 26, No. 9 , September 2011

7. N. Milivojevic, M. Krishnamurthy, A. Emadi and I. Stamenkovic, "Theory and Implementation of a Simple Digital Control Strategy for Brushless DC Generators", IEEE Transactions on Power Electronics, vol. 26, no. 11, pp. 3345-3356, Nov. 2011.

8. U. Das, P. K. Biswas, S. Debnath, "Modeling and Simulation of Open Loop Model of Brush Less DC Motor by Using MATLAB Based Software", International Journal of Electronics, Electrical and Computational System, vol.6,pp.520-526,2017, June.

9. M. Khelifa, M Mordjaoui, A. Medoued," An inverse problem methodology for design and optimization of an interior permanent magnetic BLDC motor", international journal of hydrogen energy, ScienceDirect, ELSEVIER, pp. 1-8, 2017.

10. U. Das, P. K. Biswas, S. Debnath," A Comparative Study between Load and No-Load condition of Brushless DC Motor Drives by Using MATLAB", Journal of Power Technologies 98 (3) 281-286, 2018.

11. K. Venkataratnam, "Special Electrical Machines", Universities Press (India) Private Limited.

12. U. Das, P. K. Biswas, S.Parek "Performance Analysis for Open Loop Brushless DC Motor Drive", International Journal of Engineering and Advanced Technology (IJEAT), Volume-8 Issue-6, August 2019,pp-1220-1228.

13. U. Das, P. K. Biswas, "Speed Response Optimisation of A Bldc Motor Drive with Ga-Based Classical Controller Tunning”, International Journal of Innovative Technology and Exploring Engineering (IJITEE), Volume-9 Issue-3, January 2020, pp-2167-2172

\section{AUTHORS PROFILE}

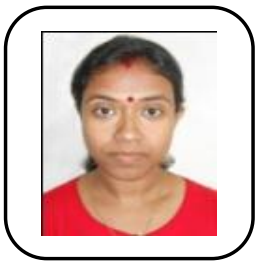

Upama Das was born in Agartala city, Tripura, India. She did her diploma from Polytechnique Institute Narsingarh, Agartala, Tripura, India and B.Tech from College of Engineering Kolagha under WBUT, India. She got her M. Tech Degree from the National Institute of Technology Agartala, Tripura, India, in Instrumentation specialization and currently pursuing a $\mathrm{PhD}$ degree at the Department of Electrical and Electronics Engineering, National Institute of Technology, Mizoram, India. She is working as an Assistant Professor in Electrical and Electronics Engineering, National Institute of Technology Mizoram, Aizawl, India. Her research interests include Power electronics Converters and Machine Drives, instrumentation, and control. E-mail: upama.eee@nitmz.ac.in

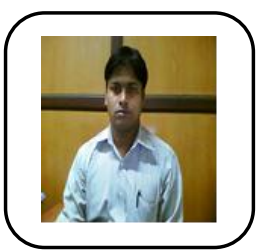

Pabitra Kumar Biswas accomplished his B.Tech from Asansol Engg. College, WBUT, India. He obtained his ME. Degree (EE Power Electronics and Drives) in 2007 from Bengal Engineering and Science University, West Bengal, India and $\mathrm{PhD}$. Degree in Electrical Engineering in 2013 from National Institute of Technology, Durgapur, India. He is currently serving as an Assistant Professor in Electrical and Electronics Engineering in the National Institute of Technology, Mizoram, India. He has published a number of research papers in National/International Conference and Records/Journals. He has a springer book chapter and filed three patents. He has also one enduring DST-SERB project. He has about 12 years of academic as well as research involvement in repute. His research fascinations comprise Electromagnetic Levitation System, Active Magnetic Bearing and Power electronics Converters, PMSM and BLDC Motor Drives and Renewable energy. E-mail: pabitra.eee@nitmz.ac.in 